HNO 2008 $\cdot 56: 21-26$

DOI 10.1007/s00106-007-1652-3

Online publiziert: 19. Dezember 2007

(c) Springer Medizin Verlag 2007

Redaktion

H. Iro, Erlangen
P. Senn ${ }^{1} \cdot$ S. Heller ${ }^{2}$

${ }^{1}$ Universitätsklinik für Hals- Nasen- und Ohrenheilkunde, Kopf- und Halschirurgie, Inselspital, Bern

2 Departments of Otolaryngology - Head \& Neck Surgery and Molecular and Cellular Physiology, Stanford University School of Medicine, Standford

\title{
Stammzellbasierte Ansätze zur Therapie von Innenohrerkrankungen
}

\begin{abstract}
In den letzten Jahren haben verschiedene Forschergruppen nach Wegen gesucht, Stammzellen für die Regeneration verlorener Haarzellen und anderer Innenohrzellen heranzuziehen. Obwohl vielversprechende Arbeiten in der Grundlagenforschung veröffentlicht wurden, sind klinisc he Anwendungen noch nicht verfügbar. Ziel dieser Übersicht ist es, die grundlegenden Eigenschaften von Stammzellen und den heutigen Stand der Forschung in Bezug auf die Entwicklung von Innenohrtherapien kurz vorzustellen.
\end{abstract}

Das Innenohr des Säugetiers verfügt nicht über eine effektive Regenerationskapazität. Ein Verlust von Haarzellen im Corti-Organ führt deswegen bei allen Säugetieren, insbesondere auch beim Menschen, zu einem irreversiblen Hörverlust. Um die Folgen eines innenohrbedingten Hörverlusts zu kompensieren, sind Menschen deswegen seit jeher auf Hilfsmittel angewiesen (• Abb. 1). Obwohl mit zunehmender Technisierung unserer Gesellschaft die Hörgeräte immer kleiner und feiner wurden, blieb das Therapieprinzip im Wesentlichen lange unverändert: Durch Schallverstärkung wird eine vermehrte Reizung der verbleibenden Haarzellen im Innenohr angeregt. Erst das Kochleaimplantat funktionierte nach einem grundsätzlich neuen Prinzip. Erstmals war es nun möglich, bei vollständi- gem Fehlen der Haarzellen durch direkte Reizung des Hörnervs Höreindrücke zu vermitteln - ein enormer Erfolg der modernen Medizin.

\section{(2) Ein Verlust von Haarzellen im Corti-Organ führt zu einem irreversiblen Hörverlust}

Verlorene Haarzellen im Innenohr zu regenerieren, wäre ein weiterer, vielversprechender Ansatz, um insbesondere den innenohrbedingten Hörverlust kausal zu therapieren. Neu ist dieser Ansatz nicht: Vögel, Amphibien und Fische kompensieren einen Innenohrhörverlust seit Millionen von Jahren durch Regeneration verlorener Haarzellen. Es wird angenommen, dass diese Regeneration von Zellen im Innenohr ausgeht, die Merkmale von Stammzellen zeigen.

\section{Grundbegriffe}

Selbsterneuerung und asymmetrische Zellteilung sind die wichtigsten Eigenschaften einer Stammzelle [22]. Wenn eine Stammzelle sich asymmetrisch teilt, entstehen 2 unterschiedliche Tochterzellen: eine neue Stammzelle, die morphologisch und funktionell eine exakte Kopie der Mutterzelle darstellt (Selbsterneuerung), und eine stärker differenzierte Tochterzelle, häufig eine Vorläuferzelle (Progenitorzelle), die sich direkt oder nach weiteren Teilungen zu gewebespezifischen Zellen entwickelt (• Abb. 2; [4]).
Die Potenz einer Stammzelle gibt Aufschluss über die Vielfalt an gewebetypischen Zellen, die aus ihr differenziert werden können. Die befruchtete Eizelle und embryonale Stammzellen (s. nächster Abschnitt) werden gemäß dieser Definition als totipotent bezeichnet, weil aus diesen Zelltypen jede einzelne Zelle des gesamten Organismus entstehen kann. Die nächstkleinere Potenz wird Pluripotenz genannt und bezeichnet die Fähigkeit einer Stammzelle, sich in Zelltypen aller 3 Keimblätter, Ektoderm, Mesoderm und Entoderm, zu differenzieren. Die Multipotenz ist die kleinste beschriebene Potenz und bedeutet, dass sich eine Stammzelle in verschiedene Zelltypen eines einzelnen Keimblatts differenzieren kann.

Eine weitere Eigenschaft von Stammzellen ist das Wachstum in eng zusammenhängenden, klonalen Verbänden. Wird ein Anheften dieser Zellverbände an der Kulturschale verhindert, bilden sich frei schwebende Sphären (- Abb. 3; $[5,15,20])$.

\section{Embryonale Stammzellen}

Embryonale Stammzellen werden aus der inneren Zellmasse der Blastozyste, dem 5-6 Tage alten Embryo, gewonnen (- Abb. 4) und gelten als totipotent. Sie können aus diesem Grunde zur Genese sämtlicher Zelltypen im Körper oder eines gesamten Tierorganismus verwendet werden. Transgene Tiere werden bei- 


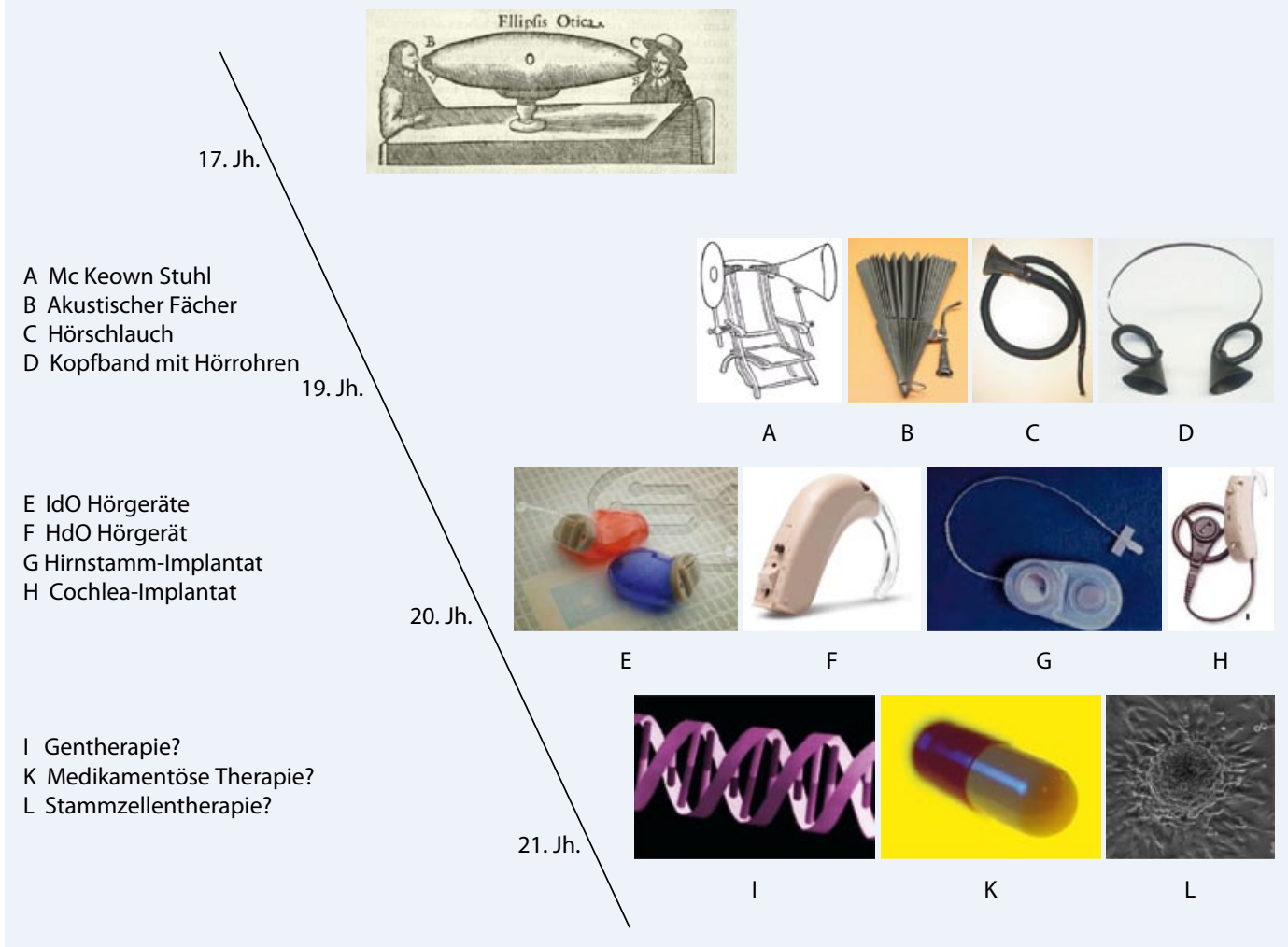

Abb. $1<$ Evolution der Hörhilfen

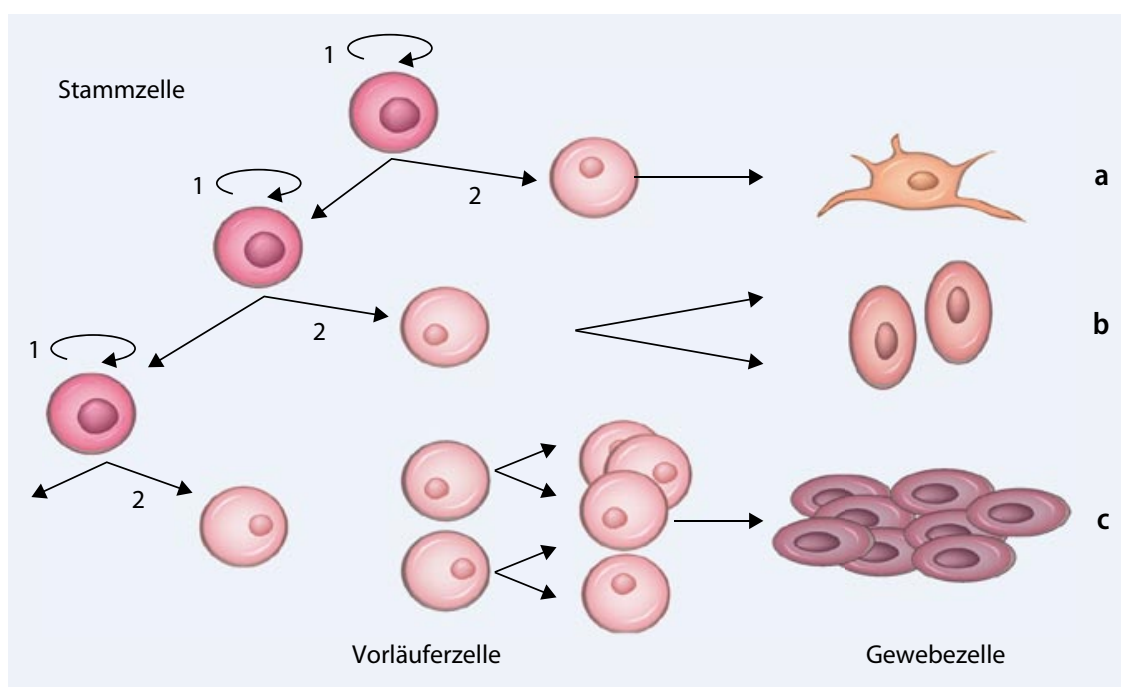

Abb. $2 \Delta$ Selbsterneuerung (1) und asymmetrische Teilung (2) sind definierende Eigenschaften einer Stammzelle. Eine Vorläuferzelle kann sich a direkt, nach b einer oder $\mathbf{c}$ mehreren, symmetrischen Teilungen zur Vervielfachung der Zellzahl in gewebetypische Zellen entwickeln

spielsweise aus genveränderten, embryonalen Stammzellen gezüchtet. Trotz ihres großen Potenzials sind embryonale Stammzellen nicht uneingeschränkt und unbedenklich einsetzbar. Die Gewinnung der Stammzellen ist ethisch umstritten, unter anderem, weil die Blastozyste bei der Entnahme obligat zerstört wird.

\section{Adulte Stammzellen}

Stammzellen finden sich in verschiedenen Organen des adulten Organismus und sind üblicherweise für Nachschub verlorener Gewebezellen verantwortlich. Adulte Stammzellen finden sich also hauptsächlich in Organen mit hohem Zellumsatz, wie Knochenmark, Haut oder
Darm. Die tägliche Produktion von mehreren Milliarden differenzierten Blutzellen über schnell teilende Progenitorzellen, ausgehend von adulten Blutstammzellen im Knochenmark, ist ein eindrückliches Beispiel für die Effizienz eines stammzellbasierten Systems (• Abb. 2c). Blutstammzellen sind die bisher am besten erforschten und die Einzigen, welche schon breite Verwendung im klinischen Alltag bei der Therapie von Blutkrebserkrankung gefunden haben.

Adulte Stammzellen wurden aber auch in Organen mit geringem Zellumsatz, wie Hirn [3, 5], Herz [1, 16], Retina [14] oder besonders interessant für den HNO-Arzt - Innenohr [9] gefunden. In der Regel gelten adulte Stammzellen als pluripotent, jedoch mit einer Vorbestimmung (,commitment") für bestimmte Zelltypen. Man kann also aus einer Innenohrstammzelle am einfachsten eine Innenohrzelle herstellen. Es ist aber auch möglich, eine Leber-, Herz- oder Hautzelle herzustellen, das bedingt dann aber eine stärke Einflussnahme auf die Stammzellen oder deren Progenie [9]. 


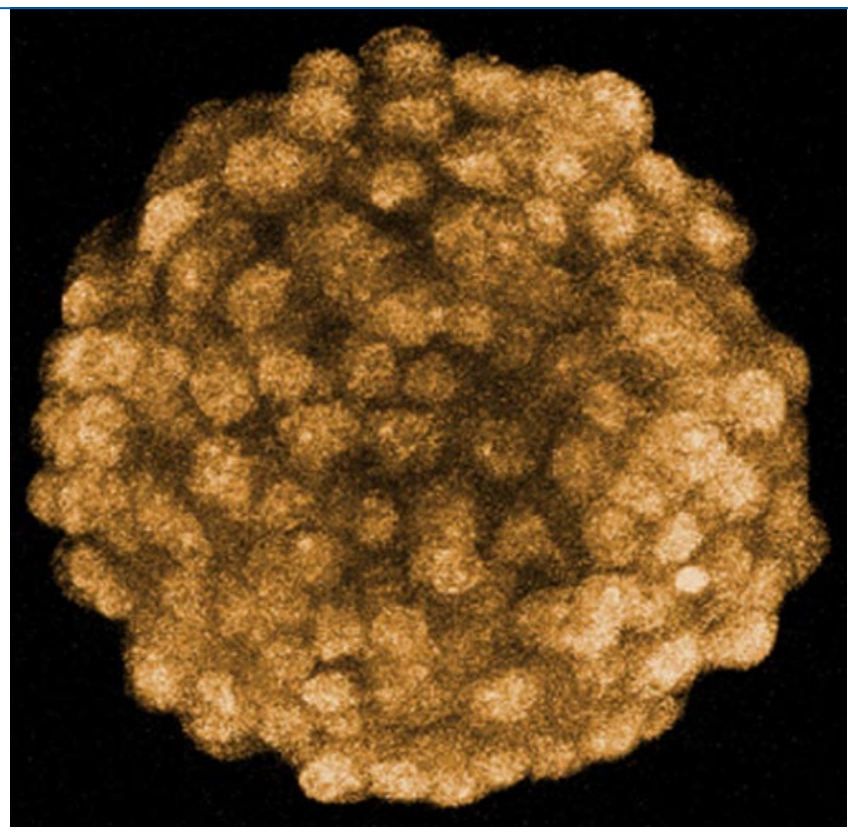

Abb. $3<$ Die Sphäre ist ein frei schwebender, klonaler Zellverband, der ausgehend von einer Stammzelle gebildet wird

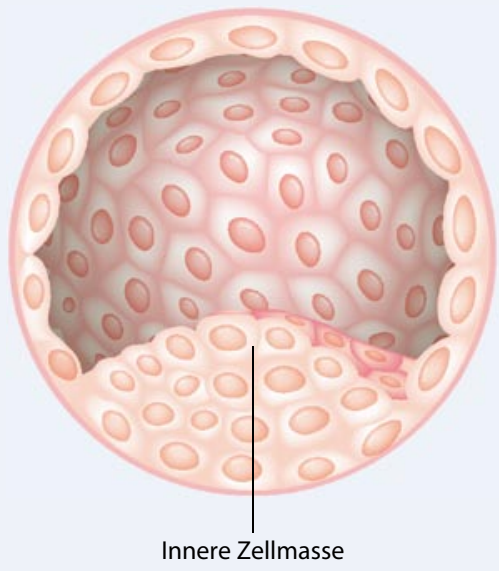

Abb. $4 \Delta$ Die innere Zellmasse der Blastozyste ist die Quelle für embryonale Stammzellen

\section{Adulte Stammzellen im Innenohr}

Ein erstes Zeichen für die Präsenz von Stammzellen im Innenohr war die Beobachtung, dass dissoziierte Zellen aus dem Corti-Organ von Ratten sich in frei schwimmende Kolonien, sog. Sphären, entwickeln konnten. Nach 2 Wochen waren zudem neu generierte Haarzellen in diesen Sphären nachweisbar [12]. Den Autoren gelang der Nachweis aber nicht, dass die Sphären ausgehend von einzelnen, sich selbst erneuernden Stammzellen wachsen.

Dieser Nachweis gelang bei Sphären aus dem Utrikel der adulten Maus [9]. Außerdem wurde gezeigt, dass diese Sphären nach Transplantation in den sich entwickelnden Hühnerembryo zur Gewebebildung in Organen aller 3 Keimblätter beitrugen (Pluripotenz).

Nachfolgende Studien bei der Maus ergaben den Nachweis ähnlicher Stammzellen im sensorischen Epithel der vestibulären Ampulla, dem Sacculus, im Corti-Organ, der Stria vascularis und dem Spiralganglion $[18,23]$. Bei der Ratte wurden Progenitorzellen im Bereich des äußeren Sulkus, lateral des Corti-Organs gefunden [25]. Eine wichtige Arbeit aus dem Labor von Rask-Andersen erbrachte zudem erstmals den Nachweis stammzellähnlicher Zellen im menschlichen Innenohr. Aus Operationspräparaten des Spiralganglions von erwachsenen Patienten konnten sich teilende, neuronale Zellen isoliert werden [19]. Dieselbe Zellpopulation wurde zudem im Spiralganglion des Meerschweinchens gefunden [19]. Einen Überblick über die bisher bekannten Stammzellpopulationen in den verschiedenen Organen des Innenohrs zeigt $\bullet$ Abb. 5.

Offenbar gibt es bedeutende Unterschiede zwischen den verschiedenen Stammzellpopulationen des Innenohrs. Im Gegensatz zu Stammzellen aus den vestibulären Organen, verlieren kochleäre Stammzellen ihre Stammzelleigenschaften während der Adoleszenz weitgehend [18]. Gleichzeitig werden in der Kochlea Zellzyklus-Inhibitoren, vor allem p27Kip1, aufreguliert [11].
HNO 2008 $56: 21-26$

DOI 10.1007/s00106-007-1652-3

(c) Springer Medizin Verlag 2007

\section{P. Senn · S. Heller}

\section{Stammzellbasierte}

Ansätze zur Therapie von Innenohrerkrankungen

\section{Zusammenfassung}

Das große Potenzial von Stammzellen zur Regeneration verlorener Gewebezellen wird zunehmend in allen Fachbereichen der modernen Medizin erkannt. Abgesehen von Blutstammzellen haben Stammzellen aber noch nicht Einzug in klinische Therapieformen gehalten. Die heutigen Experimente mit Stammzellen für die Therapie von Innenohrerkrankungen sind im Bereich der Grundlagenforschung anzusiedeln. Mehrere vielversprechende Arbeiten haben bewiesen, dass morphologisch und immunologisch differenzierbare Innenohrzellen wie Haarzellen, Stützzellen und auditorische Nervenzellen, in vitro und in vivo aus verschiedenen Stammzelltypen generiert werden können. Bisher haben aber noch keine Studien funktionelle Resultate in Bezug auf das Hörvermögen oder die vestibuläre Funktion geliefert.

\section{Schlüsselwörter}

Stammzelle $\cdot$ Haarzelle $\cdot$ Hörnerv . Regeneration $\cdot$ Innenohr

\section{Stem-cell-based approaches for treating inner ear diseases}

\section{Abstract}

The capacity of stem cells to regenerate lost tissue cells has gained recognition among physicians. Despite the successful use of blood stem cells for treating blood cancers, other stem cell types have not yet been widely introduced into clinical practice. Therapy options involving stem cells for inner ear diseases consequently have not been implemented. Nonetheless, several reports have recently been published describing the generation of morphologically and immunologically distinctive inner ear cell types-such as hair cells, supporting cells, and spiral ganglion neurons-from stem cells. Although promising, all of these studies still lack functional results regarding hearing restoration or vestibular function.

\section{Keywords}

Stem cell · Hair cell · Spiral ganglion

Regeneration $\cdot$ Inner ear 


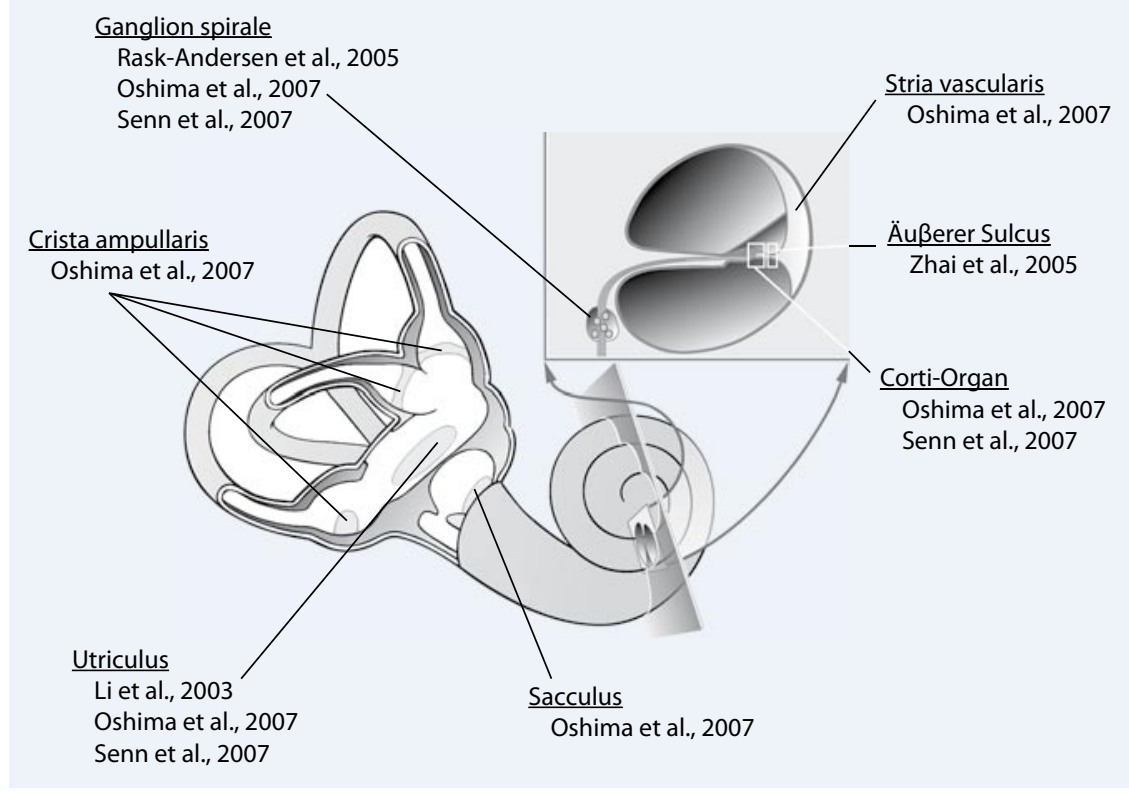

Abb. 5 \ Übersicht über nachgewiesene Stamm- und Vorläuferzellen im Säugetierinnenohr mit jeweiligen Autoren

\section{Herstellung von Haarzellen aus Stammzellen}

Adulte, pluripotente Stammzellen aus den vestibulären und kochleären Epithelien des Innenohrs eignen sich hervorragend zur Herstellung von Stützzellen und Haarzellen - vor allem in vitro (• Abb. 6a, c). Die neu gebildeten Haarzellen sind bezüglich Morphologie, Expression von haarzelltypischen Markern (z. B. Myosin VIIa) und physiologischer Funktionsweise den natürlich vorkommenden Haarzellen sehr ähnlich $[9,18,23]$. Es war zudem möglich, durch Transplantation von Stammzellen aus dem adulten Utrikelepithel der Maus in das sich entwickelnde Innenohr vom Hühnerembryo, Haarzellen (oder haarzellähnliche Zellen) in vivo aus Stammzellen zu züchten (• Abb. 6a, d; [9]). Bei diesem Experiment wurden Sphären in das otische Vesikel des 3 Tage alten Hühnerembryos eingespritzt. Sechs Tage später zeigten sich im Innenohr Haar- und Stützzellen des Hühnerembryos und dazwischen mosaikartig integriert, Haarund Stützzellen die sich von Mausstammzellen ausgehend entwickelt haben (Chimäre, $\bullet$ Abb. 6d). Es ist allerdings noch nicht klar, ob diese in vivo generierten Haarzellen funktionell sind.
Obwohl Haarzellen am einfachsten aus Innenohr-Stammzellen produziert werden können, war es aber auch möglich, haarzellähnliche Zellen aus neuralen Stammzellen des Maushirns [24], aus mesenchymalen Stammzellen des Mausknochenmarks [8] und aus embryonalen Stammzellen der Maus [10] zu züchten (• Abb. 6b).ZurGewinnungvon embryonalen Stammzellen wurden Blastozysten einer schwangeren Maus entnommen, die innere Zellmasse (• Abb. 4) entfernt und auf ernährenden Trägerzellen (bestrahlte Mausfibroblasten) gebracht und anschließend vermehrt. Im Folgenden wurden epitheliale Zellen selektioniert, die Ähnlichkeit mit otischen Vorläuferzellen hatten. Nach Expansion dieser Zellpopulation wurden die otisch vordifferenzierten Zellen anschließend entweder in vitro (• Abb. 6c) oder in vivo (- Abb. 6d) in Haar- und Stützzellen differenziert.

Trotz dieser Fortschritte war es aber bisher noch nicht möglich, verlorene Haarzellen beim Säugetier in vivo durch Transplantation von Stammzellen oder durch Aktivierung von lokalen Stammzellen in der geschädigten Kochlea zu ersetzen. Eine große Herausforderung wird sein, verlorene Haarzellen nicht nur zahlenmäßig zu ersetzen, sondern die Ersatzzellen in das hoch organisierte Corti-Organ präzise und funktionsfähig zu integrieren. Ein gutes Beispiel, um diese Herausforderung zu illustrieren, ist eine genveränderte Maus mit einer Haarzellhyperplasie. Obwohl diese Maus mehr Haarzellen aufweist als der Wildtyp, hört sie aufgrund der gestörten Architektur im Corti-Organ bedeutend schlechter [21].

Selbst wenn sich die Transplantation in das Corti-Organ in Zukunft technisch als unmachbar erweisen sollte, könnten Stammzellen eine wichtige Rolle in der zukünftigen Behandlung der Hörminderung spielen. Ausgehend von Stammzellen können große Mengen von HaarzellVorläufern oder differenzierten Haar- und Stützzellen in vitro hergestellt werden, die dann zur Erforschung von otoprotektiven oder regenerativen Substanzen in der Medikamentenentwicklung verwendet werden können.

\section{Herstellung von Spiralganglien- Nervenzellen aus Stammzellen}

Verschiedene Arbeiten haben gezeigt, dass Spiralganglien-Neurone einfach und effizient aus Stammzellpopulationen, die ebenfalls im Spiralganglion lokalisiert sind, gezüchtet werden können $[18,19$, 23]. Die so generierten SpiralganglienNeurone weisen aufgrund ihrer Morphologie und Markerexpression ( $\beta$-III-Tubulin, Neurofilament-M) weitgehende Ähnlichkeiten mit natürlich vorkommenden Spiralganglien-Neuronen auf. In Kokultur-Experimenten konnten junge Spiralganglien-Neurone zudem auf Haarzellen des explantierten Corti-Organs zuwachsen und Synapsen bilden [13]. Die von Rask-Andersen aus menschlichen Operationspräparaten i solierten SpiralganglienStammzellen waren zur Teilung und Bildung von morphologisch distinkten ZellZell-Verbindungen in der Kulturschale fähig [19].

Abgesehen von den adulten Stammzellen des Spiralganglions wurden auch andere Stammzelltypen zur Herstellung von potenziellen auditorischen Neuronen verwendet: neuronale Stammzellen aus dem Maushirn [7], Stammzellen aus dem Knochenmark der Maus [17], embryonale Stammzellen der Maus [6] und von embryonalen Stammzellen abgeleitete Progenitorzellen der Maus [2]. Die Arbeit von Corrales et al. [2] ist ein gutes Bei- 
Abb. $6 \triangleright$ Gewinnung, Vermehrung und Differenzierung von $\mathbf{a}$ adulten und b embryonalen Stammzellen, dargestellt in stark vereinfachter Form. Generierung von Haarzellen c in vitro und $\mathbf{d}$ nach Injektion in den 3 Tage alten Hühnerembryo in vivo
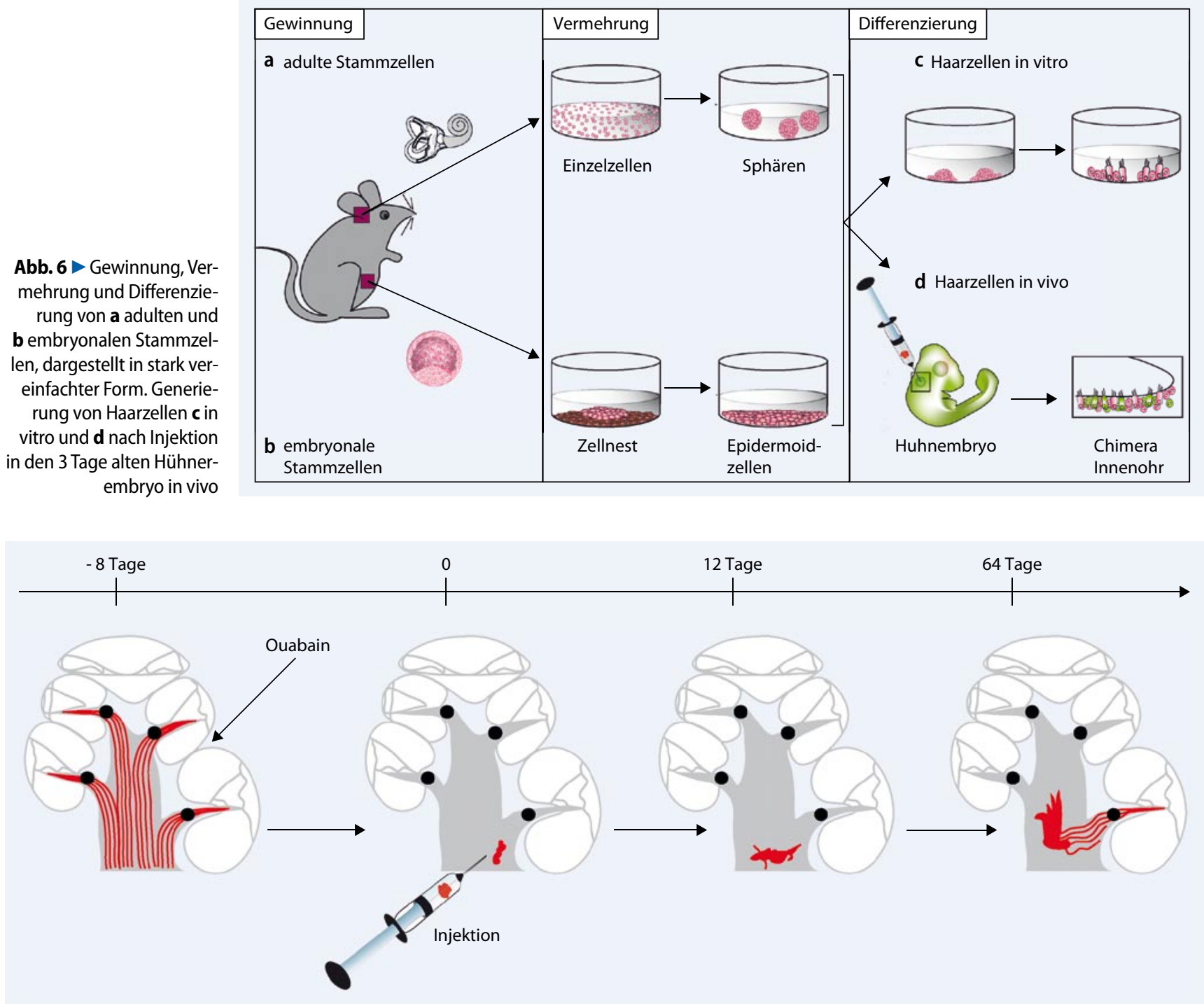

Abb. $7 \Delta$ Experiment zur In-vivo-Regeneration des Hörnervs, dargestellt in vereinfachter Form. (Nach [2])

spiel für eine schon fortgeschrittene, tierexperimentelle Arbeit zur Regeneration des Hörnervs ( $\bullet$ Abb. 7). In dieser Studie wurden auditorischen Nervenzellen im Spiralganglion der Wüstenrennmaus (Meriones unguiculatus) mittels Ouabain selektiv zerstört. Acht Tage später wurden ausgewählte Vorläuferzellen in den Nervenstamm des Hörnervs eingespritzt, aus denen sich im Verlauf der nachfolgenden Wochen neue, nervenzellähnliche Zellen differenzierten, deren Fortsätze in Richtung der Haarzellen im Corti-Organ projizierten. Trotz der partiellen, morphologischen Regeneration des Hörnervs im Bereich der Kochlea fehlen jedoch funktionelle Resultate in Bezug auf das Hörvermögen.

\section{Fazit für die Praxis}

Durch die zunehmende Präsenz von

Stammzellen in den Massenmedien werden auch vermehrt Fragen von Hörbehinderten bezüglich einer baldigen Verfügbarkeit von Stammzelltherapien geäußert. Die aktuelle Forschung in diesem Gebiet ist aber noch nicht reif für klinische Anwendungen. Die Regeneration verlorener Haarzellen in vivo durch Transplantation von Stammzellen in die Kochlea oder durch Stimulation von Stammzellen in der Kochlea wird möglicherweise noch lange nicht zu funktionellen Resultaten führen. Die komplexe Anatomie des Corti-Organs bedingt nicht nur einen zahlenmäßigen Ersatz verlorener Zellen, sondern eine perfekte In- tegration in ein hochkomplexes System. Möglicherweise könnten aber Stammzellen bei der Medikamentenentwicklung schon in absehbarer Zukunft wichtig werden. Die regenerative Kapazität der Stammzellen kann genutzt werden, um große Zahlen von Innenohrzellen in vitro für die Testung verschiedenster Moleküle und Methoden herzustellen. Auf diese Weise kann die Anzahl benötigter Versuchstiere für die Medikamentenentwicklung reduziert werden. 


\section{Korrespondenzadressen}

Dr. P. Senn

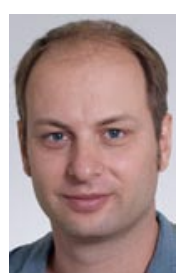

Universitätsklinik für Hals-

Nasen- und Ohrenheilkunde,

Kopf- und Halschirurgie,

Inselspital

3010 Bern

Schweiz

pascal.senn@insel.ch

Prof. Dr. S. Heller

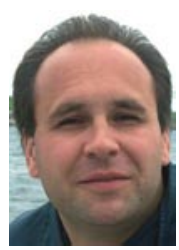

Departments of Otolaryngology - Head \& Neck Surgery and Molecular and Cellular Physiology, Stanford University, School of Medicine 801 Welch Road Stanford, CA 94305-5739, USA hellers@stanford.edu

Danksagung. Die Autoren danken Herrn Dr. Christian Grimm, Stanford University, für die Vorlage der Abb. 1 (Evolution der Hörhilfen), Frau Claudine Howald und Herrn Willi R. Hess, beide Universität Bern, für die professionelle Ausarbeitung der Abbildungen.

Interessenkonflikt. Die korrespondierenden Autoren geben an, dass kein Interessenkonflikt besteht.

\section{Literatur}

1. Beltrami AP, Barlucchi L, Torella D et al. (2003) Adult cardiac stem cells are multipotent and support myocardial regeneration. Cell 114: 763-776

2. Corrales CE, Pan L, Li H et al. (2006) Engraftment and differentiation of embryonic stem cell-derived neural progenitor cells in the cochlear nerve trunk: growth of processes into the organ of Corti. J Neurobiol 66: 1489-1500

3. Doetsch F, Caille I, Lim DA et al. (1999) Subventricular zone astrocytes are neural stem cells in the adult mammalian brain. Cell 97: 703-716

4. Gage FH, Ray J, Fisher LJ (1995) Isolation, characterization, and use of stem cells from the CNS. Annu Rev Neurosci 18: 159-192

5. Gritti A, Parati EA, Cova L et al. (1996) Multipotential stem cells from the adult mouse brain proliferate and self-renew in response to basic fibroblast growth factor. J Neurosci 16: 1091-1100

6. Hu Z, Ulfendahl M, Olivius NP (2004) Central migration of neuronal tissue and embryonic stem cells following transplantation along the adult auditory nerve. Brain Res 1026: 68-73

7. Hu Z, Wei D, Johansson CB et al. (2005) Survival and neural differentiation of adult neural stem celIs transplanted into the mature inner ear. Exp Cell Res 302: 40-47

8. Jeon SJ, Oshima K, Heller S, Edge AS (2007) Bone marrow mesenchymal stem cells are progenitors in vitro for inner ear hair cells. Mol Cell Neurosci 34 59-68

9. Li H, Liu H, Heller S (2003) Pluripotent stem cells from the adult mouse inner ear. Nat Med 9: 12931299

10. Li H, Roblin G, Liu H, Heller S (2003) Generation of hair cells by stepwise differentiation of embryonic stem cells. Proc Natl Acad Sci U S A 100: 1349513500
11. Lowenheim H, Furness DN, Kil J et al. (1999) Gene disruption of p27(Kip1) allows cell proliferation in the postnatal and adult organ of corti. Proc Natl Acad Sci U S A 96: 4084-4088

12. Malgrange B, Belachew S, Thiry M et al. (2002) Proliferative generation of mammalian auditory hair cells in culture. Mech Dev 112: 79-88

13. Martinez-Monedero R, Corrales CE, Cuajungco MP et al. (2006) Reinnervation of hair cells by auditory neurons after selective removal of spiral ganglion neurons. J Neurobiol 66: 319-331

14. Mayer EJ, Carter DA, Ren Y et al. (2005) Neural progenitor cells from postmortem adult human retina. Br J Ophthalmol 89: 102-106

15. McKay R (1997) Stem cells in the central nervous system. Science 276: 66-71

16. Messina E, De Angelis L, Frati G et al. (2004) Isolation and expansion of adult cardiac stem cells from human and murine heart. Circ Res 95: 911-921

17. Naito Y, Nakamura T, Nakagawa T et al. (2004) Transplantation of bone marrow stromal cells into the cochlea of chinchillas. Neuroreport 15: 1-4

18. Oshima K, Grimm CM, Corrales CE et al. (2007) Differential distribution of stem cells in the auditory and vestibular organs of the inner ear. J Assoc Res Otolaryngol 8: 18-31

19. Rask-Andersen H, Bostrom M, Gerdin B et al. (2005) Regeneration of human auditory nerve. In vitro/in video demonstration of neural progenitor cells in adult human and guinea pig spiral ganglion. Hear Res 203: 180-191

20. Reynolds BA, Weiss S (1992) Generation of neurons and astrocytes from isolated cells of the adult mammalian central nervous system. Science 255 : 1707-1710

21. Sage C, Huang M, Karimi K et al. (2005) Proliferation of functional hair cells in vivo in the absence of the retinoblastoma protein. Science 307: 1114 1118

22. Scott $C$ (2006) Stem cell now. Pi Press, New York

23. Senn P, Oshima K, Teo D et al. (2007) Robust postmortem survival of murine vestibular and cochlear stem cells. J Assoc Res Otolaryngol 8: 194-204

24. Tateya I, Nakagawa T, Iguchi F et al. (2003) Fate of neural stem cells grafted into injured inner ears of mice. Neuroreport 14: 1677-1681

25. Zhai S, Shi L, Wang BE et al. (2005) Isolation and culture of hair cell progenitors from postnatal rat cochleae. J Neurobiol 65: 282-293

\section{Amtliche Arzneimitteldaten für jeden zugänglich}

\section{Ab jetzt stehen jedem Staatsbürger wichtige Angaben zu Medikamenten kostenfrei über das Arzneimittel-Infor- mationssystem auf PharmNet.Bund.de zur Verfügung.}

Die Internetplattform wurde erweitert durch umfangreiche Angaben zu den in Deutschland national, zu den im europäischen Verfahren zentral oder dezentral und zu ehemals zugelassenen bzw. verkehrsfähigen Arzneimitteln. Die Verantwortung für die Inhalte liegt bei den deutschen Zulassungsbehörden.

Die durch das Deutsche Institut für Medizinische Dokumentation und Information (DIMDI) entwickelte Recherche-Oberfläche DIMDI SmartSearch ermöglicht die einfache Recherche von Arzneimittelname, Darreichungsform, Zulassungsinhaber, Zulassungsnummer, Gebrauchsinformationen (Packungsbeilagen) sowie Fachinformationen eines Medikaments. Zum Teil können auch öffentliche Beurteilungsberichte mit weiteren Informationen für Zulassungen, die ab September 2005 in Deutschland beantragt wurden, eingesehen werden.

Darüber hinausgehende Angaben, z. B. Angaben zu Parallelimporten, beschiedenen oder offenen Änderungsanzeigen, können in den vollständigen Dokumenten kostenpflichtig erworben werden.

Quelle: Bundesministerium für Gesundheit, www.bmg.bund.de 